\title{
STRUCTURE OF CESARO SECOND ORDER FUNCTION SPACES
}

\author{
NAIM L. BRAHA
}

Received 17 October, 2014

\begin{abstract}
We will define the second order Cesaro operator spaces and we will show that those spaces are Banach spaces, are separable, fulfill dominant Lebesgue theorem, are not rearrangement invariant, not reflexive and strictly convex.
\end{abstract}

2010 Mathematics Subject Classification: 46E30; 46B20

Keywords: Second Cesaro operator, dominant theorem, rearrangement, reflexive, strictly convex

\section{INTRODUCTION}

In [3] the Cesaro function space is defined as follows:

$$
\operatorname{Ces}_{p}(X)=\left\{f \in L^{0}(X): \int_{X}\left(\frac{1}{x} \int_{0}^{x}|f(t)| d t\right)^{p} d \mu(x)<\infty\right\} .
$$

And for this space several properties are shown, such as separability, dominant Lebesgue theorem etc. In [4] the second order Cesaro sequence space is defined and some of the topological properties are given. In this paper we will define the Cesaro second order function space.

Let $(X, s, \mu)$ be a $\sigma$-finite measure space and let $L^{0}=L^{0}(X)$ denote the set of all equivalence classes of complex valued measurable functions defined on $X$, where $X=[0,1]$ or $X=[0, \infty)$. Then, for $1 \leq p<\infty$, the Cesaro second function space is denoted by $\operatorname{Ces}_{p}^{2}(X)$, where $X=[0,1]$ or $X=[0, \infty)$ and is defined as follows for $1 \leq p<\infty$

$$
\operatorname{Ces}_{p}^{2}(X)=\left\{f \in L^{0}(X): \int_{X}\left(\frac{1}{x^{2}} \int_{0}^{x}|(2 x-t) f(t)| d t\right)^{p} d \mu(x)<\infty\right\}
$$

and for $p=\infty$

$$
\operatorname{Ces}_{\infty}^{2}(X)=\left\{f \in L^{0}(X): \sup _{x \in X, x>0} \frac{1}{x^{2}} \int_{0}^{x}|(2 x-t) f(t)| d t<\infty\right\} .
$$


In what follows we will use this inequality: For any numbers $A, B$ and for any $1<p<\infty$, we have

$$
|A+B|^{p} \leq 2^{p-1}\left(|A|^{p}+|B|^{p}\right) .
$$

Proposition 1. The Cesaro function space Cesp $(X)$ is a subset of the Cesaro second order function space $\operatorname{Ces}_{p}^{2}(X)$, for $1 \leq p \leq \infty$.

Proof. Let us suppose that $f \in C e s_{p}(X)$, then we get:

$$
\int_{X}\left(\frac{1}{x} \int_{0}^{x}|f(t)| d t\right)^{p} d x<\infty .
$$

On the other side, taking into consideration (1.3), we have:

$$
\begin{aligned}
& \int_{X}\left(\frac{1}{x^{2}} \int_{0}^{x}|(2 x-t) f(t)| d t\right)^{p} d x \\
& \leq 2^{p-1} \int_{X}\left(\frac{1}{x^{2}} \int_{0}^{x}|2 x f(t)| d t\right)^{p} d x+2^{p-1} \int_{X}\left(\frac{1}{x^{2}} \int_{0}^{x}|t f(t)| d t\right)^{p} d x .
\end{aligned}
$$

Hence, inclusion follows from the last relation.

Based in the above Proposition and in Hardy inequalities (see [1])

$$
\|f\|_{\operatorname{Ces}_{p}(X)} \leq\left(\frac{p}{p-1}\right)\|f\|_{L_{p}}
$$

we get the following result.

Proposition 2. $\operatorname{Ces}_{p}^{2}(X)$, for $2<p \leq \infty$ is a generalization of $\operatorname{ces}_{p}(X)$, in the sense of inclusion and inclusion is strict.

Proof. The first part follows directly from Hardy's inequality and Proposition 1. In what follows we will prove that inclusion is strict. Let

$$
f(x)=\sum_{n=1}^{\infty} a_{n} \cdot \chi_{n^{2}-1, n^{2}}(x),
$$

where $\chi$ is the characteristic function of the interval subscripted and for $2<p<\infty$, set $a_{n}=(0,0, \cdots, \underbrace{n}_{n-t h \text { position }}, 0, \cdots)$. Then

$$
\int_{X}\left(\frac{1}{x} \int_{0}^{x}|f(t)| d t\right)^{p} d x>\int_{X}\left(\frac{1}{x} \sum_{n=1}^{N-1} n\right)^{p} d x
$$

for $(N-1)^{2}<x<N^{2}$. Also,

$$
\int_{X}\left(\frac{1}{x} \sum_{n=1}^{N-1} n\right)^{p} d x=\sum_{N=1}^{\infty} \int_{(N-1)^{2}}^{N^{2}} \frac{d x}{x^{p}}\left(\sum_{n=1}^{N-1} n\right)^{p} \sim \sum_{N=1}^{\infty} \frac{N^{4 p-3}}{2^{p}(1-p) N^{4 p-4}}=\infty .
$$


Which proves that $f(x) \notin c e s_{p}(X)$. On the other side $f(x) \in \operatorname{ces}^{2}(p)$, for $2<p \leq$ $\infty$. In fact

$$
\begin{aligned}
& \int_{X}\left(\frac{1}{x^{2}} \int_{0}^{x}|(2 x-t) f(t)| d t\right.)^{p} d x<\int_{X}\left(\frac{N(N+1)}{(N-1)^{2}}-\frac{(N-1)^{3}}{2 N^{3}}\right)^{p} d x \sim \\
& \sim \int_{X}\left(\frac{1}{2 N}\right)^{p} d x,
\end{aligned}
$$

for $0<t<x$ and $(N-1)^{2}<x<N^{2}$.

$$
\int_{X}\left(\frac{1}{2 N}\right)^{p} d x=\sum_{N=1}^{\infty} \int_{(N-1)^{2}}^{N^{2}}\left(\frac{1}{2 N}\right)^{p} d x \sim \sum_{N=1}^{\infty} \frac{1}{N^{p-1}}<\infty,
$$

for $p>2$. Hence, $f(x) \in \operatorname{ces}_{p}^{2}(X)$.

$$
\begin{aligned}
& \text { For } p=\infty \text {, set } a_{n}=(0,0, \cdots, \underbrace{n^{2}}_{n-t h \text { position }}, 0, \cdots) \text {. Then } \\
& \begin{aligned}
\sup _{x>0, x \in X} \frac{1}{x} \int_{0}^{x}|f(t)| d t & >\sup _{x>0, x \in X,(N-1)^{2}<x<N^{2}} \frac{1}{x} \sum_{n=1}^{N-1} n^{2} \\
& =\sup _{x>0, x \in X,(N-1)^{2}<x<N^{2}} \frac{(N-1) N(2 N-1)}{6 x} \\
& >\sup _{N>1} \frac{(N-1) N(2 N-1)}{6 N^{2}}=\infty,
\end{aligned}
\end{aligned}
$$

which implies that $f(x) \notin C e s_{\infty}(X)$. On the other side,

$$
\sup _{x>0, x \in X} \frac{1}{x^{2}} \int_{0}^{x}|2 x-t||f(t)| d t<\sup _{N>1} \frac{1}{2 N}<\infty,
$$

which shows that $f(x) \in \operatorname{Ces}_{\infty}^{2}(X)$.

Theorem 1. The Cesaro second order function space $\operatorname{Ces}_{p}^{2}(X)$ is a normed linear metric space with norm given by the relation:

$$
\|f\|_{C(p)}=\left(\int_{X}\left[\frac{1}{x^{2}} \int_{0}^{x}|(2 x-t) f(t)| d t\right]^{p} d x\right)^{\frac{1}{p}}
$$

and

$$
\|f\|_{C(\infty)}=\sup _{x \in X, x>0} \frac{1}{x^{2}} \int_{0}^{x}|(2 x-t) f(t)| d t \quad \text { for } \quad p=\infty .
$$

Lemma 1. If $f \in \operatorname{Ces}_{p}^{2}(X), 1<p \leq \infty$, then $f \in L_{1}(0, k)$ for any fixed positive number $k$. 
Proof. To prove this Lemma, we will follow ideas given in [2]. Let $1<p<\infty$ and $k$ any fixed positive number, then using into consideration relation (1.3), we get:

$$
\begin{aligned}
\|f\|_{C(p)}^{p} & =\int_{0}^{\infty}\left[\frac{1}{x^{2}} \int_{0}^{x}|(2 x-t) f(t)| d t\right]^{p} d x \\
& \geq \int_{k}^{\infty}\left[\frac{1}{x^{2}} \int_{0}^{k}|(2 x-t) f(t)| d t\right]^{p} d x .
\end{aligned}
$$

On the other side

$$
\begin{aligned}
& 2^{p-1} \int_{k}^{\infty}\left[\frac{1}{x^{2}} \int_{0}^{k}|(2 x-t) f(t)| d t\right]^{p} d x \\
& \geq \int_{k}^{\infty}\left[\frac{1}{x^{2}} \int_{0}^{k}|(2 x) f(t)| d t\right]^{p} d x-2^{p-1} \int_{k}^{\infty}\left[\frac{1}{x^{2}} \int_{0}^{k}|t f(t)| d t\right]^{p} d x \\
& =\frac{2^{p}\|f\|_{1}^{p}}{(p-1) k^{p-1}}+\frac{2^{p-1}}{(2 p-1) k^{2 p-1}}\left[-\left(\int_{0}^{k} t|f(t)| d t\right)^{p}\right] \\
& \geq \frac{2^{p}\|f\|_{1}^{p}}{(p-1) k^{p-1}}-\frac{2^{p-1}\|f\|_{1}^{p}}{(2 p-1) k^{p-1}} \\
& =\frac{(3 p-1) 2^{p-1}\|f\|_{1}^{p}}{(p-1)(2 p-1) k^{p-1}} .
\end{aligned}
$$

Hence, from relations (1.4) and (1.5), we get the desired result.

Second case where $p=\infty$.

Let us denote by $E=\left\{x: \frac{1}{x^{2}} \int_{0}^{x}|(2 x-t) f(t)| d t>\|f\|_{C(\infty)}\right\}$. From definition of the space $\operatorname{Ces}_{p}^{2}(X)$ it follows that $\mu(E)=0$. In $E^{c}$, we can choose real number $x_{k}$ such that $x_{k}>k$ and

$$
\frac{1}{x^{2}} \int_{0}^{x}|(2 x-t) f(t)| d t \leq\|f\|_{C(\infty)} \Rightarrow \int_{0}^{x}|(2 x-t) f(t)| d t \leq x^{2} \cdot\|f\|_{C(\infty)} .
$$

On the other side we have this estimation:

$$
\int_{0}^{x}|(2 x-t) f(t)| d t \geq \int_{0}^{x}|2 x f(t)| d t-\int_{0}^{x}|t f(t)| d t \geq x \int_{0}^{x}|f(t)| d t .
$$

Hence,

$$
\|f\|_{1} \leq x_{k} \cdot\|f\|_{C(\infty)}
$$


Theorem 2. The Cesaro second order function space Ces $2(X)$, for $1<p<\infty$, is a Banach space under the norm:

$$
\|f\|_{C(p)}=\left(\int_{X}\left[\frac{1}{x^{2}} \int_{0}^{x}|(2 x-t) f(t)| d t\right]^{p} d x\right)^{\frac{1}{p}} .
$$

Proof. Let $\left(f_{n}\right)$ be any Cauchy sequence of functions belonging to $\operatorname{Ces}_{p}^{2}(X)$. Then for every $\epsilon>0$, there exists an integer $n(\epsilon)$ such that

$$
\left\|f_{m}-f_{n}\right\| \leq \epsilon \text { for all } m, n \geq n(\epsilon) .
$$

By Lemma 1 every $\left(f_{n}\right) \in L_{1}(0, k)$ for any fixed $k \in \mathbb{N}$. Let us denote by $f=$ $f_{m}-f_{n}$, from Lemma 1 it follows that $\left(f_{n}\right)$ is a Cauchy sequence related to the norm in the $L_{1}(0, k)$. In particular, for $k=1$ the sequence $\left(f_{n}\right)$ has a subsequence converging a.e., on $(0,1)$. Let $f_{n}^{0}=f_{n}$, and for any positive integer $k$, let $\left(f_{n}^{k}\right)$ be a subsequence of $f_{n}^{k-1}$ converging a.e., on $(0, k)$. Then diagonal sequence $\left(f_{k}^{k}\right)$ converges a.e., on $(0, k)$ to some measurable function $f$. Now we will estimate the difference $\left\|f-f_{n}\right\|_{C(p)}$ as $n \rightarrow \infty$. For any fixed $x$ and Fatou's Lemma we have:

$$
\begin{aligned}
\int_{0}^{x}\left|(2 x-t)\left(f(t)-f_{n}(t)\right)\right| d t & =\int_{0}^{x} \lim _{k \rightarrow \infty}\left|(2 x-t)\left(f(t)-f_{n}(t)\right)\right| d t \\
& \leq \liminf _{k} \int_{0}^{x}\left|(2 x-t)\left(f_{k}^{k}(t)-f_{n}(t)\right)\right| d t
\end{aligned}
$$

Let $\phi_{k}(x)=\left(\frac{1}{x^{2}} \int\left|(2 x-t)\left(f^{k}(t)-f_{n}(t)\right)\right| d t\right)^{p}$. Then by applying Fatou's Lemma again we get:

$$
\begin{aligned}
\int_{0}^{\infty} \liminf \phi_{k}(x) d x & \leq \liminf \int_{0}^{\infty} \phi_{k}(x) d x \\
& =\liminf \left\|f_{k}^{k}-f_{n}\right\|_{C(p)}^{p}<\epsilon^{p}, \text { for } n>N(\epsilon) .
\end{aligned}
$$

Thus $\left\|f-f_{n}\right\|_{C(p)}<\epsilon$ for every $n>N(\epsilon)$ and fixing one such $n$, the inequalities

$$
\|g\|_{C(p)} \leq\left\|f-f_{n}\right\|_{C(p)}+\left\|f_{n}\right\|_{C(p)}<\infty,
$$

shows that $f \in \operatorname{Ces}_{p}^{2}(X)$.

Theorem 3. Let $\left(f_{n}\right)$ be a sequence of measurable functions on $\operatorname{Ces}_{p}^{2}(X)$ such that

$$
\lim _{n \rightarrow \infty} f_{n}(x)=f(x)
$$

exists for almost every $x \in(0, \infty)$. If there is a function $g \in \operatorname{Ces}_{p}^{2}(X), 1<p<\infty$, such that

$$
\left|f_{n}(x)\right| \leq g(x) \quad \text { a.e. }, n=1,2, \cdots
$$

then $f \in \operatorname{Ces}_{p}^{2}(X)$ and $\left\|f_{n}-f\right\|_{C(p)} \rightarrow 0$, as $n \rightarrow \infty$

We omit the proof of the Theorem, because it is similar to Theorem 4 in [2]. 
Theorem 4. $C e s_{p}^{2}(X)$ is a separable space for $1<p<\infty$.

Proof. Proof of the Theorem is similar to the Theorem 5 given in [2]. For this reason we omit it.

Theorem 5. The Cesaro second order function space $\operatorname{Ces}_{p}^{2}(X)$, for $p=\infty$, is a Banach space under the norm:

$$
\|f\|_{\operatorname{Ces}_{(\infty)}^{2}}(X)=\sup _{x \in X, x>0} \frac{1}{x^{2}} \int_{0}^{x}|(2 x-t) f(t)| d t, \text { for } \quad p=\infty .
$$

Theorem 6. The Cesaro second order function space $C_{\infty} s_{\infty}^{2}(X)$ is not a separable space.

Theorem 7. The Cesaro second order function spaces $\operatorname{Ces}_{\infty}^{2}(X)$, are:

(1) Not rearrangement invariant

(2) Not reflexive

(3) Strictly convex, that is, if $\|f\|_{\operatorname{Ces}_{p}^{2}(X)}=\|g\|_{\operatorname{Ces}_{p}^{2}(X)}=1$ and $f \neq g$, then

$$
\left\|\frac{f+g}{2}\right\|_{\operatorname{Ces}_{p}^{2}(X)}<1 \text {. }
$$

Proof. (1) Let us consider the function $f(x)=\frac{1}{1-x}$, for $x \in[0,1)$. Then from Theorem 1-c, in [5], it follows that $f \in \operatorname{Ces}_{p}[0,1]$, for $1 \leq p<\infty$. And from Proposition 2 we get $f(x) \in \operatorname{Ces}_{p}^{2}[0,1]$. In other hand, rearrangement function $f^{*}=\frac{1}{t}$, for $t \in(0,1]$ is not in $\operatorname{Ces}_{p}^{2}[0,1]$. And therefore $\operatorname{Ces}_{p}^{2}[0,1]$ is not rearrangement invariant. In case where $p=\infty$, we can take the function $g(x)=\frac{1}{\sqrt{1-x}}$, for $x \in[0,1)$ and $\|g\|_{C e s_{\infty}[0,1]}=2$, respectively from Proposition 2 if follows that $g(x) \in \operatorname{Ces}_{\infty}^{2}[0,1]$. The rearrangement function for $g$ is $g^{*}=\frac{1}{\sqrt{t}}$, for $t \in[0,1)$ and after some calculations we have that $\|g\|_{\operatorname{Ces}^{2} \infty[0,1]}=\infty$. Hence, $g^{*} \notin \operatorname{Ces}_{\infty}^{2}[0,1]$.

(2) It follows directly from Proposition 2, and fact that $C e s_{p}(I)$ contains a copy of the space $L_{1}(I)$. It is known that $L_{1}(I)$ are not reflexive spaces and therefore $C e s_{p}^{2}(I)$ are not reflexive spaces.

(3) Proof is similar to the proof of Theorem 1-h given in [5]. For this reason we omit it.

\section{REFERENCES}

[1] T. G.H.Hardy and G.Polya, Inequalities, 2nd ed., ser. Series is books. London: Cambridge University Press, 1934, vol. III.

[2] B. Hassard and D.A.Hussein, "On cesaro function spaces," Tamkang J. Math., vol. III, pp. xi+626, 1973.

[3] J.S.Shiue, “A note on cesaro function space," Tamkang J. Math., vol. III, pp. xi+626, 1970. 
[4] N.L.Braha, "Some geometric properties related to the second order cesaro operators," To appear in Banach Journal of Mathematical Analysis, vol. X, pp. 12-23, 2015.

[5] L. M. S.V. Astashkin, "Structure of cesaro function spaces," Indag. Math. (N.S.), vol. 22, no. 3, pp. 234-245, 20 (2009), no. 3, 329-379., doi: 10.1016/S0019-3577(10)00002-9.

Author's address

Naim L. Braha

University of Prishtina, Department of Mathematics and Computer Sciences, Avenue Mother Teresa, No=5, Prishtina, 10000, Kosova

E-mail address: nbraha@yahoo.com 